\title{
Model of Effective Maritime Security Management in Shipping Industries Business Continuity
}

\author{
Ade Supandi, Arief Daryanto, Luky Adrianto and Bunasor Sanim \\ Bogor Agricultural Institute, IPB Bogor, Indonesia
}

\begin{abstract}
Indonesia is a maritime country with very busy shipping activities. It is important to ensure shipping safety and security. Until now, there are still frequent disruptions to shipping security, namely hijacking and piracy. The objective of this study is to examine the relationship between effective maritime security management with business continuity. The Analytic Network Process (ANP) method was used to examine the priority of factors in effective maritime security management in business continuity. The results of calculations with ANP give priority results of business continuity and effective maritime security management. The priority criteria for business continuity are: risk management function with a priority of 0.495 is the criteria with the highest priority. Then successively, Process of maintaining business with a priority of 0.231 , plan documentation of 0.164 and management supervision with priority 0.110 . The priority criteria of effective maritime security management priority in business continuity are: business partner security with a priority of 0.221 , security culture with a priority of 0.193 , incident handling and continuity of operations with a priority of 0.146 , management and employee commitment with priority of 0.112 , communication and documentation with priority of 0.079 , system and security procedure policy with priority of 0.077 , security assessment with priority of 0.072 , process control with priority of 0.071 and improved sustainable security with priority of 0.029 . Management of well-managed maritime safety and security management can have an impact on supply chain management including when in danger and in high disturbances. Thus, effective maritime security management is able to provide support for the continuity of the shipping industry business.
\end{abstract}

Key words: Maritime security management, business continuity, security assessment, effective, supply chain, Indonesia

\section{INTRODUCTION}

Indonesia is the largest archipelagic country in the world consisting of 17,499 large and small islands with a coastline reaching $95,181 \mathrm{~km}$ and $75 \%$ of its territory in the form of the ocean which is 5.8 million $\mathrm{km}^{2}$ and located in a cross position between two oceans namely the Indian Ocean and the Pacific Ocean. Data from the Indonesia National Ship Owner Association (INSA), combined with data from the Anonymous (2018), informed that there are 3,918 sea transport companies and 1,600 companies that are members of INSA with 12,500 ships while the number of valid vessels registered at the Indonesian ship classification agency is 10,580 units of ships which means $84.64 \%$.

There are various shipping activities in the territory of Indonesia which is followed by various negative impacts in the form of robbery, piracy, terrorism, environmental degradation, maritime abduction, illegal weapons and human trafficking, drug smuggling by sea (cargo ships/containers), maritime environmental security, cargo theft and others. More attention from shipping companies is needed in the crime of piracy, piracy and theft of facilities on board and luggage. Agencies related to efforts to maintain shipping security and safety, namely the Indonesian Navy has the main duty to uphold the law and maintain security in the sea of national jurisdiction in accordance with the provisions of national law and international law.

Based on shipping activities occurring in Indonesia, data from the Navy's Operations Staff shows that hijacking and piracy still occur (Table 1).

The data shows that there are still occurrences of shipping insecurity that shipping companies need continuously to be anticipated. Another indication of

\begin{tabular}{lcccc}
\multicolumn{5}{c}{ Table 1: Data on hijacking and piracy in Indonesian waters in 2014-2017 } \\
\hline & Years & & & \\
Criminal Act & 2014 & 2015 & 2016 & 2017 \\
\hline Hijacking & 18 & 21 & 8 & 8 \\
Piracy & 9 & 1 & 1 & 2 \\
Total & 27 & 22 & 9 & 10 \\
\hline
\end{tabular}

Indonesian Navy Operations Staff in 2018

Corresponding Author: Ade Supandi, Bogor Agricultural Institute, IPB Bogor, Indonesia 
Table 2: Ship accident data based on data from the NTSC investigation in 2018

\begin{tabular}{|c|c|c|c|c|c|c|c|c|}
\hline \multirow[b]{2}{*}{ Years } & \multirow[b]{2}{*}{ No. of accident } & \multicolumn{7}{|c|}{ Kinds of accident } \\
\hline & & Sinking & Burn/explode & Collision & Aground & Others & Died/lost & Hurt \\
\hline 2012 & 4 & 0 & 2 & 2 & 0 & 0 & 13 & 10 \\
\hline 2013 & 6 & 2 & 2 & 2 & 0 & 0 & 65 & 9 \\
\hline 2014 & 7 & 2 & 3 & 2 & 0 & 0 & 22 & 4 \\
\hline 2015 & 11 & 3 & 4 & 3 & 1 & 0 & 85 & 2 \\
\hline 2016 & 18 & 6 & 4 & 3 & 3 & 2 & 46 & 18 \\
\hline 2017 & 34 & 6 & 14 & 6 & 6 & 2 & 42 & 2 \\
\hline Jan-Mar 2018 & 9 & 5 & 2 & 0 & 0 & 2 & 33 & - \\
\hline
\end{tabular}

knkt.dephub.go.id

Table 3: Maritime Liability Insurance Claims for 2011-2017

\begin{tabular}{lcl}
\hline Causes & Percentage & Losses (US\$) (billion) \\
Human error & 75 & 1.600 \\
Accidental nature/damage & 18 & 0.384 \\
Natural hazards & 1 & 0.021 \\
Negligence/poor maintenance & $<1$ & $<0.021$ \\
Failure to provide service & $<1$ & $<0.021$ \\
Other & 5 & 0.107 \\
Total & 100 & Almost 2.115 \\
\hline
\end{tabular}

Safety and shipping review, 2018

unsafe ship operation in the sea territory is the incident of ship crashes, burning, collisions and aground. The following table is a ship accident released by the National Transportation Safety Committee (NTSC) investigation data up to March, 2018 (Table 2).

The number of accidents that occurred from 2012 until 2017 shows an increasing trend and in the period of 2015-2017 the increase was more rapid than before. Besides that, the NTSC data (2018) notes several major incidents of ships sinking in June and July 2018. On July 3 , the Lestari motor vessels carrying passengers from Bulukumba to Selayar, South Sulawesi sank in the waters of Pabeddilang Beach, causing at least 34 people dead. On June 29, a fast boat carrying illegal Indonesian worker (TKI) from Tawau, Malaysia collided with another speedboat in Sebatik Sea, North Kalimantan, causing 8 people dead and 2 others missing. On June 18, 164 people disappeared and 3 people died after KM Sinar Bangun sank in the Toba Lake, North Sumatra.

The condition of insecurity in the form of hijacking and piracy as well as various accidents caused by sinking, burning, collisions and grounding is one of the most important discussions in supply chain security management because it can disrupt supply chain security in general.

Furthermore, according to Allianz Global Corporate and Specialty (AGCS) analysis of nearly 15,000 maritime liability insurance claims between 2011 and 2017 shows that human error reaches $75 \%$ of the value of all the analyzed claims, equivalent to more than $\$ 1.6$ billion. Furthermore, natural damage/accidents reached 18\%, equivalent to $\$ 0.384$ billion. In detail the 2011-2017 insurance claims in Table 3.
An annual review of trends and developments in shipping losses and safety: Based on the total insurance claims, it is estimated that Indonesia's total maritime insurance claims will reach the US $\$ 220$ million. This is an economic value which in macro and micro needs to be concerned for shipping security and safety in Indonesia.

On the other hand, effective management of maritime service industry companies, especially, the shipping industry, in anticipating and managing security systems is important. Effective maritime security management in the shipping industry includes security culture, management and employee commitment, security assessment, security policy, systems and procedures, documentation and communication, process control, continuous security improvement, security incidents handling and continuity of operations, business partner security at shipping companies (Sadovaya and Thai, 2015). With an effective capability in managing maritime security management, not only increases the anticipation of maritime security but more than that it is expected to contribute to the sustainability of the company's business because of the shipping business that is full of natural and crime challenges.

In the conclusion of Varbanova (2018) research, it is explained that the benefits of improved security measures for all supply chain participants to provide protection from hazards that usually occur during the transportation process. Particularly in the container supply chain, it will be able to reduce the possibility of hazards that occur during the transportation process, so that, they can avoid or reduce the risk of greater losses. Recognizing the driving factors, understanding their interests and the influence of each on the company enables management of vulnerabilities (Fazli and Masoumi, 2012).

Furthermore, due to the increasing effectiveness of maritime security management in the shipping industry, it is expected that it will enhance the business continuity of the shipping industry. In accordance with the research of Hecht (2002), Bajgoric (2006), Bajgoric and Moon (2009), Castillo (2005), Swartz et al. (2003), Thai and Grewal (2007) and Anonymous (2016), business continuity is a priority of management supervision, risk management functions 
and documentation of the plan and documentation of the process of maintaining business. The continuity of the shipping industry business is needed in the development of maritime countries such as Indonesia to contribute to the sustainability of national development.

Research question: Based on the background above, the research problems can be formulated as follows: what are the priorities of management oversight, risk management functions, documentation of plans and the process of maintaining business on the business continuity of shipping companies? What are the priorities for the effectiveness of maritime security management in the business continuity of shipping companies?

Literature review: Research on shipping safety was carried out by Bueger (2015) and Liwang (2015). From previous research on maritime security and safety, several important points, namely:

Maritime security and safety include piracy and armed robbery, maritime terrorism, illegal trade through the sea, namely trafficking in narcotics, arms trade, human trafficking, global climate change, theft of cargo and others. Maritime security challenges continue to evolve and maybe hybrid: a mixture of traditional and irregular warfare, terrorism and/or organized crime that is interconnected and unpredictable. Operational requirements and maritime collaboration that displays maritime domain weaknesses, so that, it is recommended for political, military and business decision makers.

The efforts needed to improve the quality and efficiency of maritime security governance include various rules both international, national and business, in general, to be able to anticipate maritime insecurity. Important factors that need to be considered in the implementation of shipping safety policies are safety equipment that must be provided, the feasibility of the ships, good navigation and supervision of the shipping administration.

Prepare shipping operations by supporting conscious risk-taking related to shipping security that the description and quantification of operations in risk analysis are very important for ship safety and security. In addition, the need for shipping safety and security risk analysis, considering shipping is a business with high risk and brings business processes with high value.

Previous research on business continuity was carried out by Kildow (210), Marisa and Oigo (2018) and Makila (2014). From previous research on business continuity, there are several important notes that need to be considered, namely:

A business continuity program is an important program, so that, the company can survive the occurrence or event that hit the company including if the company experiences security and safety disruptions in the process of its business operations. Business resilience must be targeted to vulnerability, so that, resources will be applied optimally through effective management by finding a balance between vulnerability and resilience, so that, when risk increases in the business context it can be anticipated to reduce losses and maintain business continuity.

Management of business continuity is an important part of the health of a company whose success depends on a combination of various elements of the company. Previous research relates to the relationship of maritime security and business continuity including (Rice and Spayd, 2005; Barnes and Oloruntoba, 2005; Marisa and Oigo, 2018; Gould et al., 2010; Sadovaya and Thai, 2015; Scholliers et al., 2016; Chinonyerem et al., 2017; Filipovic et al., 2018). From research related to shipping security and safety, business continuity can be shown several important points, namely:

The economic loss of an accident shows a significant impact on the output of sea transportation sub-sector, increased risk of crisis situations will increase the degree of development of business continuity management. There are shipping companies that influence the function of risk management and the process of maintaining a business. Management of security is a very important factor in ensuring the continuity of the company business in dealing with uncertain situations. Effective maritime security management has a positive effect on the performance of shipping company organizations.

\section{MATERIALS AND METHODS}

Maritime security management in shipping companies: A large number of countries and international actors place maritime security on their security agenda. This priority is reflected in several governments and intergovernmental strategies for maritime security that were published in the past decade including the United States, Britain, France, India, NATO, the European Union (EU) and the African Union (AU). In multilateral statements such as the G7 declaration on maritime security and in the research of the International Ocean Annual Conference, the theme continues to be echoed.

The effectiveness of maritime security management can be interpreted as the level of success achieved by maritime security management in managing maritime security. In the academic literature, the most frequently mentioned management approaches include risk management (Thai and Grewal, 2007), quality management (Urciuoli et al., 2010), business continuity management 
(Gutierrez et al., 2007), disaster management (Macdonald and Corsi, 2013), crisis management, layered approach and total security management. Based on the registered approach, the total framework is introduced in the field of maritime chain security and supply management. Among them is the Supply Chain Security Management Model (SCSMM) developed by Gutierrez et al. (2007), a framework for Supply Chain Security Management (FSCSM) proposed by Closs et al. (2008), the Conceptual Model of Effective Maritime Security (CMEMS) introduced by Thai and Grewal (2007) and a maritime security management system (IDID) proposed by Thai and Grewal (2007).

With detailed consideration of this framework, a list of important criteria for effective maritime security management is introduced in the (Sadovaya and Thai, 2015 ) studies, namely a security culture; management and employee commitment, security assessment, security policies, systems and procedures, documentation and communication, process control, continuous security improvement, security incidents handling and continuity of operations and business partner security.

Continuity of the shipping industry business: Some experts defined business continuity such as Hecht (2002), Bajgoric (2006) and Bajgoric and Moon (2009). The definition of business continuity from (Hecht, 2002; Bajgoric 2006; Bajgoric and Moon, 2009) is very compatible with the definition of Castillo (2005) which explicitly describes business continuity as the ability to maintain income flows through a crisis or "the ability to retain a revenue stream through a crisis".

The other definition was developed by Swartz et al. (2003), Khir (2009), Speight(2011) and Anonymous (2016). These definitions managerially explain the company related to its ability to guarantee the continuity of its business. Based on the various definitions above in this study, business continuity can be formulated as a process of managing exposure to internal and external threats that can disrupt the availability of business operations of the company. This involves supervision of management, risk management functions and documentation of plans and processes to maintain the business in the event of a business disruption. Furthermore, according to Anonymous (2016), each factor can be explained as follows: management supervision includes:

- Employee safety and health

- Timely and accurate assessment of an incident and any secondary impacts

- Personnel and resources are available to support timely and affordable recovery

- Property and financial losses are minimized
The function of risk management includes:

- Identification of important assets, key business processes, important dependencies and the impact of potential business disruptions

- Document recovery time goals for important systems and processes

- Set minimum requirements and restore point objectives to restore business operations to acceptable levels

- Prioritize recovery procedures from identified recovery time goals

- Analyze service level agreements with vendors and suppliers

- Identify and document important assets

Documentation of the plan includes:

- Crisis management plan

- Recovery plan due to accident or disaster

- Business recovery plan

The process of maintaining business includes:

- Public trust because it is able to settle obligations well, financially, commercially and morally

- The company's ability to continue to pay its debt owed

- The company's ability to solve business problems faced

- Trust to get credit

Effective maritime security management and continuity of shipping industry business: According to Button and Thibault (2005) explained the link between the costs incurred for increasing security with the security gained and increasing benefits. Graphically it can be presented in Fig. 1. Conceptually, several important points can be explained as follows: there are costs to increase the provision of security as the effort to get benefits from its security. If there is asymmetric information or at least the perception of asymmetric information between the government and the general public, the effect of its prudence tends to be greater and can cause excessive security.

The benefits of increased security because the results of subjective risk assessments can be faster than the costs used in implementing additional security measures, so that, there are unlimited perceived benefits to improving security.

Thus, the need for assessment and cost determination are used in maintaining and improving 


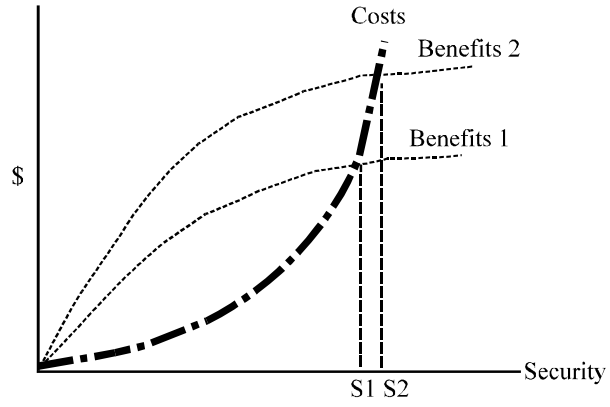

Fig. 1: Expenditures for optimal security

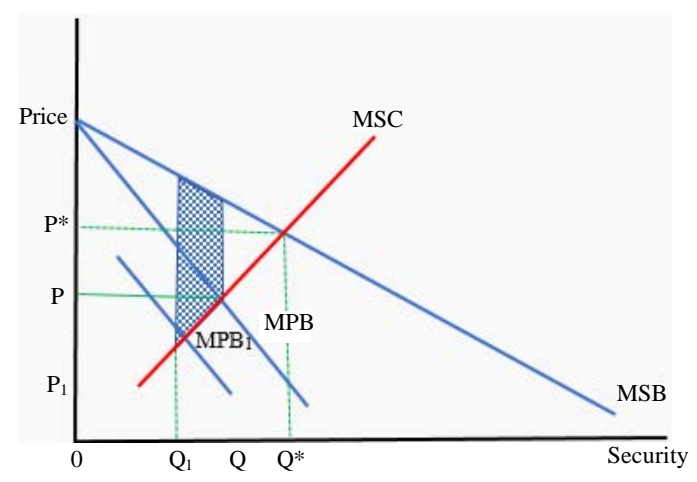

Fig. 2: Increased prosperity due to increased security

security in order to obtain optimal profits. The next explanation in more detail is stated by Button (2016) (Fig. 2). The image can be summarized in a number of important points, the following explanation:

The MPB curve can be seen as a company that is willing to pay for a certain level of security. The company will buy security to the point where its marginal benefits match the additional security costs, namely $\mathrm{Q}$ at the price of $\mathrm{P}$. Because there are some unusual forms of security, companies may collectively want more security. This is reflected in the MSB curve. If we consider this, the optimal level of security provision is $\mathrm{Q}^{*}$ at the cost of $\mathrm{P}^{*}$.

Any public action or action that makes the company feel safer will push the marginal profit curve in providing company security to MPB 1 from the previous MPB, not affecting the marginal MSB public profit curve and thus, optimum social profit is still $Q^{*}$, so, there profit as big as shaded areas. So that with good management companies with government support pay for security QQ but companies themselves feel that they enjoy the marginal profit equivalent to when they only pay $Q$ even though they only pay $\mathrm{Q}_{1}$.

Furthermore, the relationship between the implementation of security management in terms of the costs that must be borne is endorsed by Varbanova (2018) in his research conclusion. The strict security procedures of the CSI will lead to delay in transportation processes, especially, for carriers and shippers. A detailed analysis has been made regarding the cost of security measures and its effect on the supply chain container. The benefits of increased security measures are higher for all supply chain participants, allowing protection from usual hazards during the transportation process.

Thus, the implementation of strict security procedures in the transportation process, especially, in the container supply chain will be able to reduce the possibility of hazards that occur during the transportation process, so that, it can avoid or reduce the risk of greater losses.

Varbanova's view is similar to Smith (2016) view which explains that shipping companies are aware that here are many regulatory guidelines given to them regarding ship safety and security. However having a Business Continuity Management System (BCMS) that runs in place must be seen by shipping companies as an equally important component for their coast-based operations. To prepare for the risk of disruption, shipping companies must meet the requirements to implement a feasible and tested business continuity management plan.

The unavailability of one or several of these key element elements can potentially cause the entire company to crash. Developing, implementing and instilling business continuity into the company's management system will help reduce the impact of disruptions on work practices and service delivery. The business continuity management system will help companies to minimize their risk and the possibility of them experiencing disruption. However, if the worst happens, a good BCMS will help with effective and fast recovery after helping protect the company's operations. Furthermore with the increasing effectiveness of maritime security management in the shipping industry, it is expected that it will enhance the business continuity of the shipping industry.

In accordance with research from Hecht (2002), Bajgoric (2006), Bajgoric and Moon, 2009, Castillo (2005), Swartz et al. (2003), Speight (2011), Anonymous (2016) that business continuity is a priority of management supervision, risk management functions and documentation of the plan and documentation of the process of maintaining business. The continuity of the shipping industry business is needed in the development of maritime countries such as Indonesia to contribute to the sustainability of national development. Based on the theory from Smith (2016) and reinforced by Varbanova (2018), taking into account the cost, profit and security 


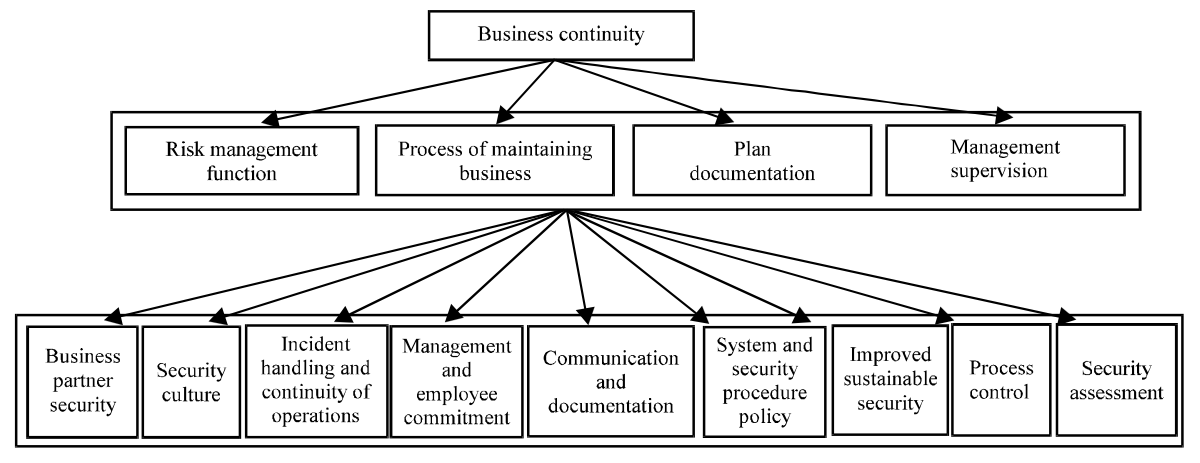

Fig. 3: Research conceptual framework

theories of the Button and Thibault, the relationship between effective maritime security management and business continuity can be explained in the relationship between effective maritime security management indicators and business continuity indicators. The relations are developed in detail using explanations of effective maritime security management from Sadovaya and Thai (2015), Sadovaya (2015) and business resilience from Hecht (2002), Bajgoric (2006), Bajgoric and Moon (2009), Castillo (2005), Swartz et al. (2003), Speight (2011) and Anonymous (2016).

Research conceptual framework: Based on the discussion by Hecht (2002), Bajgoric (2006), Bajgoric and Moon (2009), Castillo (2005), Swartz et al. (2003), Speight (2011) and Anonymous (2016), it can be compiled the research conceptual framework (Fig. 3).

ANP Model from the framework of the above research refers to the writing technique of the analyze network process model as stated by Saaty (2005). A hierarchy is composed of goals, levels of elements and connections between the elements. These connections are lower levels in oriented only to elements. A network has clusters of elements with the elements in one cluster being connected to elements in another cluster (outer dependence) or the same cluster (inner dependence). A hierarchy is a special case of a network with connections going only in one direction.

Time and place of research: The research was conducted from June, 2018 to December, 2018 with literature review activities, gathering data on the shipping companies in Indonesia. Furthermore, research was carried out on shipping companies, marine security agencies, Directorate General of Sea Transportation and the Indonesian Navy. The research subjects are people who expert in shipping and businesses.
Research design: In this study, a quantitative approach was used with the survey method. The survey method is a method that uses a questionnaire as a data collection tool. Quantitative approaches can be interpreted as research methods based on positivist philosophy and explaining phenomena by collecting numerical data which are analyzed using mathematically based methods (Muijs, 2004). The technique of sampling uses an expert choice, that is people who really understand the ins and outs of shipping companies and shipping activities. These paper studies the research subjects included shipping companies in Jakarta, the sea security agency, the Director General of Sea Transportation and the Indonesian Navy, then the data and facts from the collected questionnaires will be tested by Analysis Network Process (ANP).

Population: The population used to collect data in this study are stakeholders in the shipping industry including shipping industry, Directorate General of Sea Transportation, Maritime Security Agency and the Indonesian Navy. The shipping industry population includes 1,600 shipping companies members of the Indonesia National Ship Owner Association (INSA) with the number of valid vessels registered at the Indonesian Ship Classification Agency of 10,580 ships.

Sampling technique: While the sampling technique is used proportional non-random sampling method in the form of an expert choice, especially, the shipping industry and shipping activities. In this study, it consists of 2 variables with 9 indicators and 4 indicators, so that, a total sample of 45 people from all stakeholders can be used which are closely related to the represented shipping industry, namely:

- The 30 practitioners from shipping companies 
- The 5 officials who are in accordance with the duties of their responsibilities from the Directorate General of Sea Transportation

- The 5 officials who are in accordance with the duties of their responsibilities from the Marine Security Agency

- The 5 officials who are in accordance with the duties of their responsibilities from the Indonesian Navy

\section{RESULTS AND DISCUSSION}

Modeling results: Modeling is done based on a hypothetical model. In this ANP Model, the priority criteria and relationships between criteria, alternative priorities for each criterion and relationship between alternatives are considered. Modeling can be presented as in Fig. 4.

Data processing: The results of processing data with Super Decision Software obtained the following results. From the results of the limit matrix, further synthesis is carried out to obtain the final results of alternative weights that are effective maritime security management for the purpose of business continuity. Furthermore, the priority criteria for business continuity based on the synthesis of calculations are obtained:
Business continuity priority: From the calculation of the weighted supermatrix in accordance with Table 4, the priority results of the criteria for business continuity are obtained as follows:

- Risk management function with the priority of 0.495

- The process of maintaining business with a priority of 0.231

- Plan documentation with priority 0.164

- Management supervision with priority 0.110

Thus, on business continuity, the risk management function priority is 0.495 . Its priority is the highest priority. Then, successively maintaining business processes priority is 0.231 , plan documentation priority is 0.164 and management supervision priority is 0.110 . Based on the order of priority, business continuity is largely determined by the risk management function. This is consistent with the research of Filipovic et al. (2018) which explains the influence of different crisis situations

Table 4: Altemative priorities for ideals, normal and raw

\begin{tabular}{lc}
\hline Criteria & Priority \\
\hline Risk management function & 0.495 \\
Process of maintaining business & 0.231 \\
Plan documentation & 0.164 \\
Management supervision & 0.110 \\
\hline
\end{tabular}

Primary data, processed

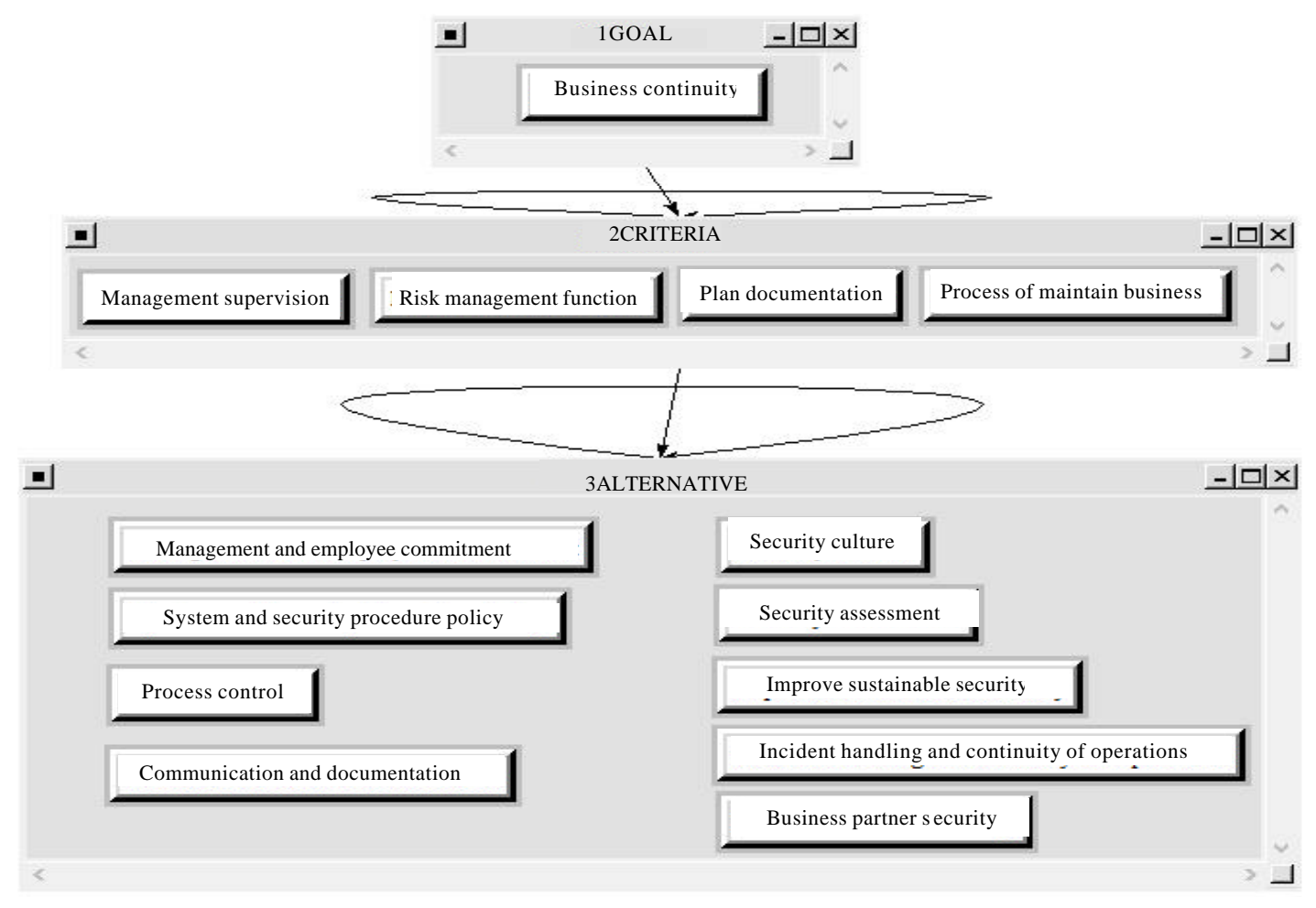

Fig. 4: Analytic network process ANP Model 
on the development of business continuity management. The correlation between the crisis situation and the development of business continuity management shows that the increased risk of a crisis situation will increase the degree of business continuity management development. In addition, strategic and operational risks are more influential in developing business continuity management from natural disasters. Also, unwanted risks affect the development of business continuity management more than intentional risk. The main contribution of this study lies in modeling the development of business continuity management related to different crisis situations and the possibility of recurrence of crises. The important thing is the need to develop business continuity management in the face of uncertainty due to the distuption of security and safety of business processes.

Maritime security management priorities effective in business continuity: Based on the synthesis as presented in Fig. 4, the priority of effective maritime security management on business continuity is in the following order:

- Business partner security with a priority of 0.221

- Security culture with a priority of 0.193

- Incident handling and continuity of operation with a priority of 0.146

- Management and employee commitment with a priority of 0.112

- Communication and documentation with a priority of 0.079

- System and security procedure policy with a priority of 0.077

- Security assessment with a priority of 0.072

- Process control with a priority of 0.071

- Improved sustainable security with a priority of 0.029

Thus, ineffective maritime security management to support business continuity, it needs to prioritize implementation in the order above. Based on the results of the analysis, the four largest weights of effective maritime security management are obtained, namely: business partner security, then, security culture incident handling and continuity of operations and management and employee commitment.

Business continuity improvement: Based on the results of the research and discussion, it is important to underline that the increase in the business continuity of shipping companies is very important considering that businesses in the shipping sector are high-risk business sectors. Thus, efforts to increase business continuity are a necessity. This is consistent with the opinion of Kildow (2010) that a comprehensive business continuity program that includes all internal and external links in the supply chain is important if the business wants to survive after a major disaster. From the research conducted by Betty, it can be said that the business continuity program is an important program, so that, the company can survive the occurrence of events that hit the company including if the company experiences security and safety disruptions in the process of operating its business.

The use of an adequate budget to improve safety conditions must always be a priority while taking into account the amount of the budget spent and the value of the safe condition obtained, so that, there are no miscalculations that can have an impact on the company's business losses. This is in accordance with the theory of Button and Thibault (2005) which explains the relationship between the costs incurred for increasing security and increasing benefits. In increasing business continuity, the top priority is the function of risk management with a priority of 0.4951 . Then the process of maintaining business with priority is 0.2309 , documentation of plan with priority is 0.1643 and management supervision with priority is 0.1097 . Therefore, shipping companies need to be encouraged to improve their risk management functions.

Another managerial implication is to refer to the opinion of Kildow (2010) that for employees, companies that have a comprehensive business continuity program can mean protecting their livelihoods and salaries by helping ensure that the business will continue and develop. Ignoring supply chain considerations in the business continuity planning process will result in a plan that is likely to fail when the next disaster strikes. Thus, the continuity of a guarded business will provide peace for employees in carrying out their role in the company and of course will have a good impact on the company.

Increasing the effectiveness of maritime security management in supply chains: The effectiveness of maritime security management that is increasingly effective will have an impact on increasing business continuity. Therefore, it is necessary to increase according to the weight of the priority of the maritime security agenda. The biggest priority we pay attention to is the security of business partners, the culture of security, handling incidents and continuity of operations as well as management and employee commitments.

It should be noted in increasing the effectiveness of maritime security in accordance with the theory of Button and Thibault (2005) which explains the relationship between the costs incurred for increasing security 
obtained and increasing benefits. If the security costs are more effective, it will have an impact on improved benefits and a better level of security. Thus, the effectiveness of maritime security management for shipping companies needs to be developed to lead to better business continuity.

Based on the opinion of Rice and Spayd (2005), explained that supply chain security management influences the continuity of supply chain business processes. The guarantee of the most significant investment in security is the development of the company's ability to continue operations the continuity of the supply chain, so that, it can maintain its economic livelihood in the face of significant disruptions.

Besides that in the supply chain, according to the results of research from Van Dyk et al. (2008) that important maritime security measures for sea transportation have implications for the supply chain. So, it is important to ensure the integration of compliance with daily operations and supply chain implications.

\section{CONCLUSION}

The priority criteria for business continuity are: the risk management function with a priority of 0.4951 is the criteria with the highest priority. Then successively, the process of maintaining business with a priority of 0.2309 , plan documentation of 0.1643 and management supervision with priority 0.1097 .

The maritime security management priority that is effective in business continuity is: business partner security with a priority of 0.226 , security culture with a priority of 0.141 , system and security procedure policy with priority of 0.126 , management and employee commitment with priority of 0.115 , incident handling and continuity of operations with a priority of 0.110 , process control with priority of 0.089 , communication and documentation with priority of 0.077 , improved sustainable security with priority of 0.065 and security assessment with priority of 0.051 .

Management of well-managed maritime safety and security management can have an impact on supply chain management including when in danger and in high disturbances. Thus, effective maritime security management is able to provide support for the continuity of the shipping industry business.

\section{ACKNOWLEDGEMENT}

The researchers greatly acknowledge the support from Bogor Agricultural University (IPB Bogor Indonesia) for providing the necessary resources to carry out this research work. The researchers are also grateful to the Anonymous reviewers and journal editorial board for their many insightful comments which have significantly improved this study.

\section{REFERENCES}

Anonymous, 2013. The economic impact of the UK maritime services sector: Shipping. London, England, UK. https://webcache. googleusercontent. com/search?q=cache:a_iCP37 dMBgJ:https://www. maritimeuk.org/documents/16/Shipping_The_econ omic_impact_of_the_UK_Maritime_Services_Sect or_QoJotMP.pdf $+\& \mathrm{~cd}=3 \& \mathrm{hl}=$ en\&ct $=$ clnk \&gl $=$ pk

Anonymous, 2016. Building and maintaining a business continuity program. McAfee, Santa Clara, California, U $\quad S \quad A$

https://www.mcafee.com/enterprise/en-us/assets/w hite-papers/wp-business-continuity.pdf

Anonymous, 2018. Safety and shipping review. Allianz, Munich, Germany. https://www.agcs.allianz. com/news-and-insights/news/safety-shipping-revie w-2018.html

Bajgoric, N. and Y.B. Moon, 2009. Enhancing systems integration by incorporating business continuity drivers. Ind. Manage. Data Syst., 109: 74-97.

Bajgoric, N., 2006. Information technologies for business continuity: An implementation framework. Inf. Manage. Comput. Secur., 14: 450-466.

Barnes, P. and R. Oloruntoba, 2005. Assurance of security in maritime supply chains: Conceptual issues of vulnerability and crisis management. J. Int. Manage., 11: 519-540.

Bueger, C., 2015. Learning from piracy: Future challenges of maritime security governance. Global Affairs, 1: $33-42$.

Button, K. and M. Thibault, 2005. The political economy of maritime container security. Proceedings of the 46th Annual International Conference on Transportation Research Forum, March 6-8, 2005, Transportation Research Forum, Washington, DC., USA., pp: 1-19.

Button, K., 2016. The Economics and Political Economy of Transportation Security. Edward Elgar Publishing, Cheltenham, UK., ISBN:9781785367779, Pages: 192.

Castillo, C., 2005. Disaster preparedness and business continuity planning at Boeing: An integrated model. J. Facil. Manage., 3: 8-26.

Chinonyerem, N.T., I. Calistus, O. Geraldine and M. Ntor-Ue, 2017. Analysis of vessel-based marine accidents and the economic risks to Nigeria. J. Water Resour. Ocean Sci., 6: 72-84. 
Closs, D., C. Speier, J. Whipple and M.D. Voss, 2008. A framework for protecting your supply chain. Supply Chain Manage. Rev., 12: 38-45.

Dionne, G., 2013. Risk management: History, definition and critique. Risk Manage. Insurance Rev., 16: 147-166.

Fazli, S. and A. Masoumi, 2012. Assessing the vulnerability of supply chain using analytic network process approach. Intl. Res. J. Appl. Basic Sci., 3: 2763-2771.

Filipovic, D., M. Kristo and N. Podrug, 2018. Impact of crisis situations on development of business continuity management in Croatia. Manage. J. Contemp. Manage. Issues, 23: 99-122.

Gould, J.E., C. Macharis and H.D. Haasis, 2010. Emergence of security in supply chain management literature. J. Trans. Secur., 3: 287-302.

Gutierrez, X., J. Hintsa, P. Wieser and A.P. Hameri, 2007. Voluntary supply chain security program impacts: An empirical study with BASC member companies. World Customs J., $1:$ 39-48.

Hecht, J.A., 2002. Business continuity management. Commun. Assoc. Inf. Syst., 8: 444-450.

Khir, C.A., 2009. The Practitioner's Definition Guide: Safety \& Security. Singapore Logistics Association, Singapore, ISBN:9789814266185, Pages: 263.

Kildow, B.A., 2010. The supply chain and business continuity: Preparing to survive the next disaster. Proceedings of the 95nd Annual International Conference on Supply Management (ISM's), April 25-28, 2010, Institute for Supply Management, Tempe, Arizona, USA., pp: 1-9.

Liwang, H., 2015. Risk-based ship security analysis-a decision-support approach. Ph.D Thesis, Chalmers University of Technology, Gothenburg, Sweden.

Macdonald, J.R. and T.M. Corsi, 2013. Supply chain disruption management: Severe events, recovery and performance. J. Bus. Logist., 34: 270-288.

Makila, M., 2014. Resilience as a way to improve business continuity: A multiple case study with large Nordic companies. Master's Thesis, Department of Information and Service, School of Business Economy, Aalto University, Espoo, Finland.

Marisa, R. and D. Oigo, 2018. Influence of organizational resources and structure on business continuity management of private security firms in Kenya. J. Hum. Resour. Manage., 6: 18-25.

Muijs, D., 2004. Doing Quantitative Research in Education with SPSS. 1st Edn., SAGE Publication, New Delhi, ISBN: 978-0761943839, Pages: 240.
Rice, J.B. and P.W. Spayd, 2005. Investing in supply chain security: Collateral benefits. MBA Thesis, IBM Center for the Business of Government, Washington, DC., USA.

Saaty, T.L., 2005. Theory and Applications of the Analytic Network Process: Decision Making with Benefits Opportunities, Cost and Risks. 3rd Edn., RWS Publications, Pittsburgh, USA., ISBN-13: 9781888603064, Pages: 352.

Sadovaya, E. and V.V. Thai, 2015. Impacts of implementation of the Effective Maritime Security Management Model (EMSMM) on organizational performance of shipping companies. Asian J. Shipping Logist., 31: 195-215.

Sadovaya, E., 2015. Effective management of maritime security in shipping companies. Ph.D Thesis, Nanyang Technological University, Singapore.

Scholliers, J., A. Permala, S. Toivonen and H. Salmela, 2016. Improving the security of containers in port related supply chains. Trans. Res. Procedia, 14: 1374-1383.

Smith, W., 2016. Shipping and business continuity management. Navigate Group, Toronto, Ontario. https://www.navigateresponse.com/newsletter/resp onse-newsletter--october-2016/shipping-and-busin ess-continuity-management

Speight, P., 2011. Business continuity. J. Appl. Secur. Res., 6: 529-554.

Swartz, E., D. Elliott and B. Herbane, 2003. Greater than the sum of its parts: Business continuity management in the UK finance sector. Risk Manage., 5: 65-80.

Thai, V.V. and D. Grewal, 2007. The maritime security management system: Perceptions of the international shipping community. Marit. Econ. Logist., 9: 119-137.

Urciuoli, L., H. Sternberg and D. Ekwall, 2010. The effects of security on transport performance. Proceedings of the 12th World Conference on Transport Research (WCTR), July 11-15, 2010, Lisbon, Portugal, pp: 1-18.

Van Dyk, E., E. Maspero and H. Ittmann, 2008. Maritime supply chain security: Navigating through a sea of compliance requirements. J. Trans. Supply Chain Manage., 2: 12-24.

Varbanova, A., 2018. Evaluating the impact of security measures on container supply chains. Intl. Sci. J., 3: 33-36

Williams, Z., 2008. Supply chain security: An institutional approach to strategies and outcomes. Ph.D Thesis, Mississippi State University, Starkville, Mississippi, USA. 